\title{
The success and failure of the adult congenital heart
}

\section{R. Thomas Collins II ${ }^{1}$}

Published online:4 March 2020

(C) Springer Science+Business Media, LLC, part of Springer Nature 2020

This special edition of Heart Failure Reviews focuses on myocardial dysfunction, or "heart failure," in the setting of adult congenital heart disease (ACHD). However, to understand better the "failure" of the heart with ACHD, it is deeply informative to understand the successes in the field of congenital heart disease. Much like atherosclerotic disease [1], ACHD is a story that begins in childhood. Knowing from whence the field has come and where it is currently informs our understanding of ACHD in critical ways that are not the case for adults with atherosclerotic heart disease and myocardial dysfunction. As such, this introduction aims to provide some context for the excellent reviews that follow.

Congenital heart defects (CHDs) are the most common structurally related group of birth defects in humans, occurring in approximately $1 \%$ of all live births [2], and are the leading cause of neonatal and infant death due to congenital issues [3]. In spite of this disease magnitude, advancements in the care of CHDs did not occur until the 1940s, a relatively short time ago. In fact, of those children born with CHD in 1940, only $20 \%$ survived to adulthood [4]. By 1960, the survival had doubled to $40 \%$, and by 1980 , survival to adulthood was $90 \%$.

The field of congenital heart disease care began with and remains a symbiotic relationship between pediatric cardiologists and congenital heart surgeons. It was Helen Taussig who saw the potential for using Alfred Blalock and Vivien Thomas' subclavian-to-pulmonary artery shunt as a therapy for tetralogy of Fallot, and with that, the first truly palliative congenital heart surgery was born in 1944 [5]. Between that surgery and the 1990s, the field ushered in the first open heart surgery, cardiopulmonary bypass, intracardiac baffling for transposition of the great arteries, the Fontan procedure for tricuspid atresia, the arterial switch operation, and the Norwood procedure [5]. As

R. Thomas Collins, II

tomcollins@stanford.edu

1 Department of Pediatrics, Division of Cardiology, and Department of Internal Medicine, Division of Cardiovascular Medicine, Stanford University School of Medicine, 750 Welch Road, Suite 321, 650-7241907, Palo Alto, CA 94304, USA surgical innovations abated, advancements in medical therapies and care accelerated into the 1990s, and by the early 2000s, eight patients with CHDs became the first to receive a transcatheter valve replacement [6].

As a result of the great success within the field, as of 2014, there were more than 1.5 million adults with CHDs in the USA [7], and that number is increasing by an estimated $5 \%$ per year [8], putting a reasonable estimate of the current population at 2 million adults. This ever-increasing population of adults with CHDs requires ongoing cardiac care. While it was previously believed that simple CHDs did not warrant ongoing care in adulthood, emerging evidence demonstrates clearly that even simple CHDs confer impacts on long-term cardiovascular risk [9]. However, the great success of the field has drastically outpaced our ability to develop the legion of cardiologists with expertise in ACHD to care for this population. While there is now an American Board of Internal Medicine subspecialty board certification in ACHD, as of June 2019, prior to the 2019 administration of the exam, there were only 302 cardiologists in the USA who have been certified [10], and a significant number of those who have been do not practice ACHD care as a primary focus - varying numbers are electrophysiologists, intensivists, and interventionalists who do not provide "general" ACHD care. Currently, there are 18 ACGME-accredited, 2-year fellowship programs, 16 of which are participating in the Match [11]. In 2019, 55\% (5/9) of the programs that participated in the Match filled their positions [12]. Thus, an exceptionally small number of trainees are pursuing training in ACHD, and this has been the case since the inception of the board examination.

Owing to the severe lack of board-certified ACHD cardiologists with currently limited hope of reinforcements in the form of trainees pursuing ACHD, if all 302 of us who are board certified focus solely on ACHD, there would be approximately 6600 patients per cardiologist. That is a number that is more than twice the number of patients Marelli and colleagues have estimated would require a regional ACHD center [13], one comprised of multiple cardiologists. Assuming a given person works 5 days per week during 48 weeks of a given year, that would necessitate each of us seeing 28 ACHD patients per day, if all patients were only seen once annually. 
While advanced practice providers are an integral part of what we do, it is clear that for the foreseeable future, if ACHD patients are to receive cardiological care, a lot of them will have to be cared for by non-ACHD-trained cardiologists.

With the reality of the lack of ACHD cardiologists in mind, this special edition of Heart Failure Reviews is meant to serve as a reference for all cardiologists caring for patients with ACHD. The goal has been to provide the congenital context for subgroups of CHDs and practical approaches to caring for them. Drs. Vaikunth and Lui begin the edition by covering general principles of heart failure in ACHD [14], and this is built upon by a review of the general approach to heart failure management to patients with ACHD [15]. Following on, Mueller et al. cover heart failure in the largest such group of patients with ACHD, that being tetralogy of Fallot [16]. The intricacies of heart failure in the setting of the adult with Ebstein anomaly [17] is then addressed before the edition turns attention to the systemic right ventricle $[18,19]$ and ultimately to perhaps the most challenging group, those with a failing Fontan circulation [20]. The value of exercise testing in the assessment of heart failure in ACHD is then reviewed by Burstein et al. [21]. Finally, the edition culminates with the role of cardiac resynchronization and implantable defibrillators in patients with ACHD [22].

Heart failure in patients with ACHD is to be expected at some point. As I have said to many trainees and colleagues, "Heart failure is a part of all congenital heart disease; it's just a matter of where they are on the spectrum." To this end, it is hoped that this edition of Heart Failure Reviews will provide useful information that will help improve the care of the growing population of adults with CHDs.

\section{Compliance with ethical standards}

Conflict of interest The author declares that he has no conflict of interest.

\section{References}

1. Berenson GS, Srinivasan SR, Bao W, Newman WP 3rd, Tracy RE, Wattigney WA (1998) Association between multiple cardiovascular risk factors and atherosclerosis in children and young adults. The Bogalusa Heart Study. N E J Med 338:1650-1656. https://doi.org/ 10.1056/NEJM199806043382302

2. van der Linde D, Konings EEM, Slager MA, Witsenburg M, Helbing WA, Takkenberg JJ, Roos-Hesselink JW (2011) Birth prevalence of congenital heart disease worldwide: a systematic review and meta-analysis. J Am Coll Cardiol 58:2241-2247. https:// doi.org/10.1016/j.jacc.2011.08.025

3. Hoffman JIE, Kaplan S, Liberthson RR (2004) Prevalence of congenital heart disease. Am Heart J 147:425-439. https://doi.org/10. 1016/j.ahj.2003.05.003
4. Warnes CA, Liberthson R, Danielson GK et al (2001) Task force 1: the changing profile of congenital heart disease in adult life. J Am Coll Cardiol 37:1170-1175

5. Collins RT, Shin AY, Hanley FL (2020) Sacrificing the future for the sake of the present. Ann Surg 271:225-226. https://doi.org/10. 1097/SLA.0000000000003432

6. Bonhoeffer P, Boudjemline Y, Qureshi SA, le Bidois J, Iserin L, Acar P, Merckx J, Kachaner J, Sidi D (2002) Percutaneous insertion of the pulmonary valve. J Am Coll Cardiol 39:1664-1669

7. Marelli AJ, Ionescu-Ittu R, Mackie AS et al (2014) Lifetime prevalence of congenital heart disease in the general population from 2000 to 2010. Circulation 130:749-756. https://doi.org/10.1161/ CIRCULATIONAHA.113.008396

8. Gurvitz MZ, Inkelas M, Lee M, Stout K, Escarce J, Chang RK (2007) Changes in hospitalization patterns among patients with congenital heart disease during the transition from adolescence to adulthood. J Am Coll Cardiol 49:875-882. https://doi.org/10.1016/ j.jacc.2006.09.051

9. Saha P, Potiny P, Rigdon J, Morello M, Tcheandjieu C, Romfh A, Fernandes SM, McElhinney D, Bernstein D, Lui GK, Shaw GM, Ingelsson E, Priest JR (2019) Substantial cardiovascular morbidity in adults with lower-complexity congenital heart disease. Circulation 139:1889-1899. https://doi.org/10.1161/ CIRCULATIONAHA.118.037064

10. https://www.abim.org/ /media/ABIM\%20Public/Files/pdf/ statistics-data/candidates-certified-all-candidates.pdf. Accessed 18 Feb 2020

11. ERAS. Adult congenital heart disease programs. In: https://services. aamc.orgeraserasstatspardisplay.cfmNAVROWPARSPECCD. Accessed 13 Feb 2020

12. National Resident Matching Program, Results and Data: Specialties Matching Service 2019 Appointment year. (2019) National Resident Matching Program, Washington, DC. Page 29

13. Marelli AJ, Therrien J, Mackie AS, Ionescu-Ittu R, Pilote L (2009) Planning the specialized care of adult congenital heart disease patients: from numbers to guidelines; an epidemiologic approach. Am Heart J 157(1):1-8

14. Vaikunth S, Lui G (2020) Heart failure with reduced and preserved ejection fraction in adult congenital heart disease. Heart Fail Rev

15. Tompkins R, Romfh A (2020) General principles of heart failure management in adult congenital heart disease. Heart Fail Rev

16. Mueller AS, McDonald D, Singh H, Ginns J (2020) Heart failure in adult congenital heart disease: tetralogy of Fallot. Heart Fail Rev

17. Schultz KE, Haeffele CL (2020) Heart failure in the adult Ebstein patient. Heart Fail Rev

18. Andrade L, Carazo M, Wu F, Kim Y, Wilson W (2020) Mechanisms of heart failure in systemic right ventricle. Heart Fail Rev

19. Carazo M, Andrade L, Kim Y, Wilson W, Wu F (2020) Assessment and management of heart failure in the systemic right ventricle. Heart Fail Rev

20. Broda CR, Downing TE, John A (2020) Diagnosis and management of the adult patient with a failing Fontan circulation. Heart Fail Rev

21. Burstein DS, Menachem JN, Opotowsky AR (2020) Exercise testing for assessment of heart failure in adults with congenital heart disease. Heart Fail Rev

22. Chubb H, Motonaga KS (2020) Cardiac resynchronization and implantable defibrillators in adults with congenital heart disease. Heart Fail Rev

Publisher's note Springer Nature remains neutral with regard to jurisdictional claims in published maps and institutional affiliations. 